\title{
UTILIZAÇÃO DE RESIDUO DE PNEUS EM ESTACAS ESCAVADAS.
}

\author{
Valério Henrique França ${ }^{1}$ \\ Newton de Oliveira Pinto Junior ${ }^{2}$
}

Adriano Souza ${ }^{3}$

Resumo: O principal objetivo deste trabalho é dar uma destinação ambientalmente correta para os resíduos de pneus proveniente do processo de recauchutagem. Sabemos que este material é produzido em grandes volumes e são lançados a natureza irregularmente causando diversos prejuízos. Um caminho ambientalmente correto é a inserção este material no concreto onde seu confinamento não causara danos a natureza. Em paralelo a sua utilização no concreto ajuda a reduzir a extração de areia, pois nesta pesquisa este material será substituído pelo resíduo. Foram realizados seis estacas em tamanho real, sendo três utilizando a borracha e as demais convencionais. Realizou-se o ensaio de reação de cargas normatizado pela NBR 12131/2006 em ambas amostras. Com isso foi possível comparar os resultados e observar o comportamento da estaca com a inserção de borracha. Com os resultados obtidos pode-se concluir que é possível a utilização dos resíduos de borracha em substituição a areia na confecção de estacas tipo escavadas.

Palavras-chave: Resíduo de pneu. Estaca escavada.

\footnotetext{
${ }^{1}$ Doutorando Engenharia Civil, UNICAMP, valerio franca@yahoo.com.br

${ }^{2}$ Professor Doutor, UNICAMP, pintojr@fec.unicamp.br

${ }^{3}$ Professor Doutor, UNESP-FEIS' adriano@dec.unesp.br
} 


\section{INTRODUÇÃO.}

Segundo organizações internacionais, a produção diária mundial de pneus novos é estimada em 2 milhões. Já o descarte de pneus velhos atinge anualmente a marca de 800 milhões de unidades. De acordo com a ANIP (Associação Nacional das Indústrias Pneumáticas) só no Brasil, em 2012, foram produzidos cerca de 62,7 milhões de pneus e quase metade dessa produção foi descartada no mesmo período (Boletim Informativo da Bolsa de Reciclagem Sistema FIEP).

Uma das preocupações é a forma de descarte deste resíduo na natureza, que em sua grande maioria tem como destino os lixões, aterros sanitários e os rios. Esta forma desordenada de descarte tem se tornado um grande problema para a sociedade. No que tange à saúde, ele tem sido um meio de proliferação do mosquito Aëdes Aegypti, devido ao acúmulo de água em sua parte interna. Para o meio ambiente, o problema causado pela disposição de pneus em aterros sanitários e lixões é grave, uma vez que eles possuem grande resistência à degradação, podendo levar até 240 anos para se decomporem.

Para dar destino aos pneus usados, não há uma tecnologia ideal, pois a definição do processo depende de fatores, tais como: volume de pneus, proximidade de mercado, tipo de consumidores, investimento necessário, além de incentivos fiscais e financeiros. Para o desenvolvimento e avanço das tecnologias voltadas para a reutilização e a reciclagem de pneus, faz-se necessário um esforço conjunto de empresas, do governo e da sociedade.

Uma forma encontrada para amenizar esse impacto trata-se da utilização das metodologias de reciclagem e reaproveitamento. Entre elas, a recauchutagem tem sido um mecanismo bastante utilizado para conter o descarte de pneus usados. O Brasil ocupa o segundo lugar no ranking mundial de recauchutagem de pneus, o que the confere uma posição vantajosa junto a vários países na luta pela conservação ambiental. Esta técnica permite que o recauchutador, seguindo as recomendações das normas para atividade, adicione novas camadas de borracha nos pneus velhos, aumentando, desta forma, a vida 
útil do pneu em 100\% e proporcionando uma economia de cerca de $80 \%$ de energia e matéria-prima em relação à produção de pneus novos (Boletim Informativo da Bolsa de Reciclagem Sistema FIEP).

Infelizmente esse processo gera um grande volume de resíduo da borracha que são descartados da mesma maneira que os pneus sendo descartado de forma desordenada afetando e prejudicando o meio ambiente.

Uma destinação ambientalmente adequada seria buscar este confinamento junto a concretos e argamassas encontrando na construção civil uma destinação adequada a este material. Este trabalho busca confinar estes resíduo em concreto utilizado em fundações.

No oeste do Estado de São Paulo é muito comum o emprego de estacas broca, escavadas a trado ou mecanicamente, sem lama bentonítica, como fundações em obras de pequeno a médio porte.

A escolha deste tipo de fundação é forçada pela ocorrência de uma camada de solo colapsível, que cobre toda a região, com espessura que varia de poucos centímetros até $30 \mathrm{~m}$ de profundidade.

Estas estacas quando empregadas como elementos de fundações, na maioria das vezes, são submetidas a esforços axiais de compressão, em alguns casos de obras de engenharia são empregadas para resistirem a esforços de tração (fundações de torres de transmissão; estruturas elevadas como caixas d'água, blocos de ancoragens, entre outros).

A avaliação da capacidade de carga de estacas pode ser feita através de métodos teóricos e semi-empíricos, sendo o último tipo amplamente utilizado na prática de fundações no Brasil. Os métodos semi-empíricos baseiam-se em ensaios in situ de penetração (CPT e SPT).

A pesquisa realizada vem dar continuidade ao programa de pesquisa que está sendo realizado no Campo Experimental de Fundações da Unesp de Ilha Solteira (FE-IS), com o primeiro trabalho de Carvalho e Souza (1990) e outros diversos já realizados e em 
andamento. Além de fortalecer o trabalho em conjunto entre pesquisadores da Faculdade de Engenharia Civil da Unicamp (FEC-Unicamp) e da Unesp de Ilha Solteira, vem corroborar com o desenvolvimento científico e sustentável.

\section{DESENVOLVIMENTO.}

O objetivo foi de desenvolver estudo comparativo da capacidade de carga de estacas broca executadas em concreto convencional e estacas broca executadas em concreto com incorporação de resíduo de borracha, ambas escavadas com trado mecânico. Estas estacas foram construídas em escala natural, com 0,30 m de diâmetro e $6,0 \mathrm{~m}$ de comprimento, dotadas de instrumentação apropriada $(0,30 \mathrm{~m}, 1,20 \mathrm{~m}$ e $5,70 \mathrm{~m}$ de profundidade), e ensaiadas por provas de carga para se obter a capacidade de carga e a relação carga versus recalque. Foi também, feito um estudo aprofundado do material "concreto com resíduo de borracha", através de análises de aderência, resistência à compressão, elasticidade e provas de carga estática. Obtiveram-se resultados satisfatórios, que garantiram a viabilidade técnica da utilização do concreto com incorporação de resíduo de borracha na confecção de estacas broca de forma econômica e segura.

\section{Procedimento Experimental}

Para a composição do concreto convencional e do com incorporação de resíduos foram usados os agregados miúdo e graúdo da região de llha Solteira-SP. Utilizou-se cimento Portland com adição de escória granulada de alto-forno (CP II32-E - fabricante Cauê), comercialmente disponível, cujas características são especificadas pela NBR11578/1997. Este cimento tem uma composição intermediária entre o cimento portland comum e o cimento portland com adições (alto-forno e pozolânico). Este cimento combina com bons resultados o baixo calor de hidratação com o aumento de resistência 
do Cimento Portland Comum. Recomendado para estruturas que exijam um desprendimento de calor moderadamente lento ou que possam ser atacadas por sulfatos.

Os resíduos de borracha de pneus, provenientes do processo de recauchutagem, foram fornecidos pela empresa "Araçá Renovadora de Pneus Ltda", localizada no município de Araçatuba - SP e estão ilustrados na figura 1.

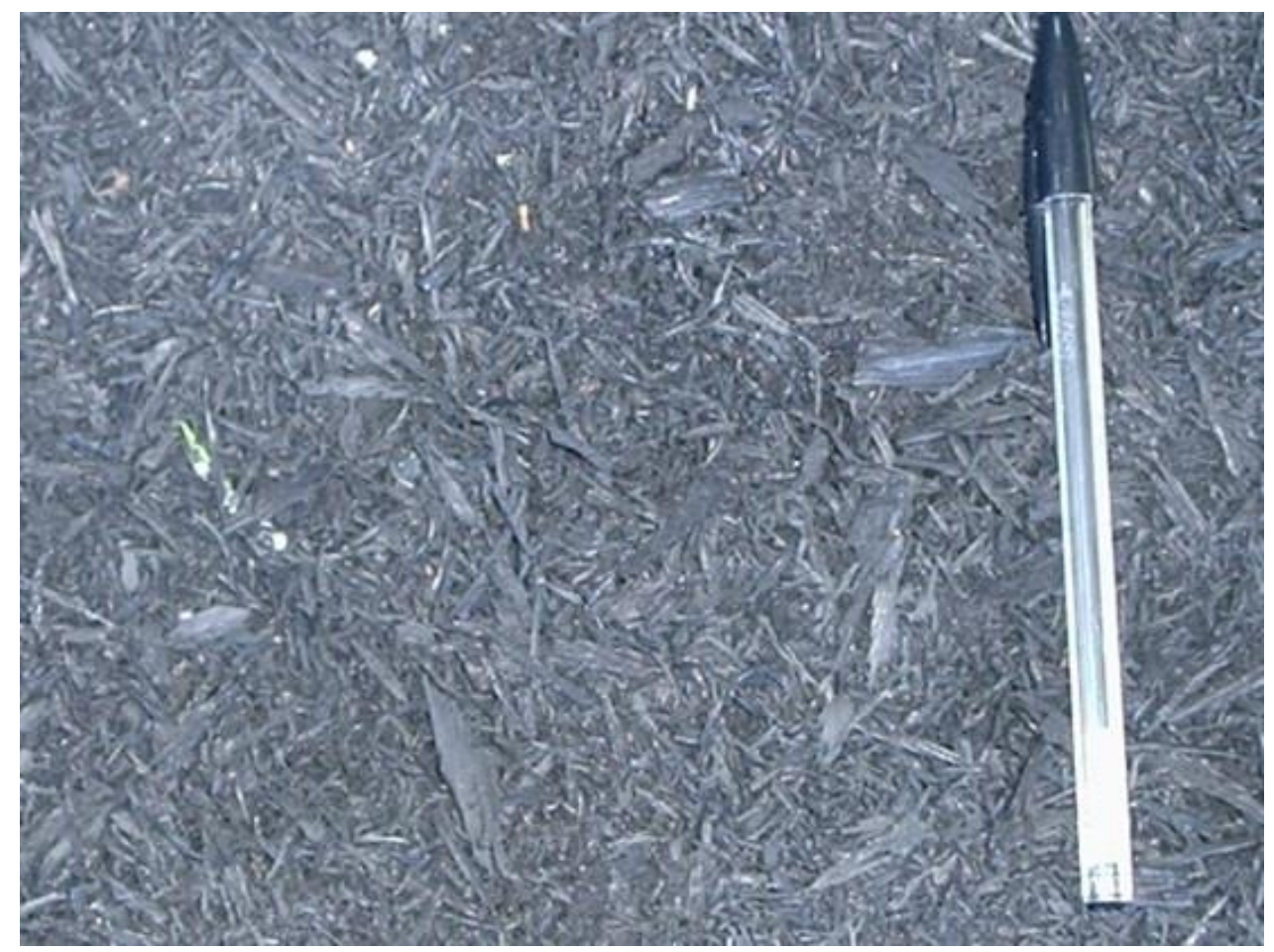

Figura 1 - Resíduos de borracha no estado natural: Fonte: França 2004.

Foram realizados todos os ensaios para caracterização dos materiais seguindo as respectivas normas brasileiras de regulamentação. Com estes resultados foi possível a confecção do traço para o concreto.

Para a composição do concreto convencional a ser utilizado em fundações foram seguidos as orientações da NBR 6122/2010.Com esses dados a composição do concreto foi experimental e o ponto de partida foi a composição utilizada por França (2004) no 
entanto para atender as instruções da NBR 6122/2010 foram necessários alguns ajuste chegando a composição ilustrada na Tabela-1.

\section{Tabela 1 - Composição Final do Concreto Convencional}

\begin{tabular}{|c|c|}
\hline Materiais & Consumo $\mathbf{~ k g} / \mathbf{m}^{\mathbf{3}}$ \\
\hline Cimento & 420,17 \\
\hline Água & 203,33 \\
\hline Areia & 837,81 \\
\hline Brita 01 & 919,43 \\
\hline
\end{tabular}

A composição do concreto com $10 \%$ de resíduo de borracha foi realizada mantendo a relação a/c e consumo de cimento igual a do concreto convencional. Os resíduos de borracha foram incorporados ao concreto em substituição à areia em volume. A composição do traço com resíduos de borracha está ilustrada na Tabela 2.

Tabela 2 - Composição do Concreto 10\% de resíduo de borracha.

\begin{tabular}{|c|c|}
\hline Materiais & Consumo $\mathbf{~ g} / \mathbf{m}^{3}$ \\
\hline Cimento & 420,17 \\
\hline Água & 203,33 \\
\hline Areia & 754,03 \\
\hline Brita 01 & 919,43 \\
\hline Borracha & 35,40 \\
\hline
\end{tabular}

Foi determinada, para as idades de 7, 28 e 56 dias, a resistência à tração, resistência média à compressão e módulo de deformação, seguindo os procedimentos estabelecidos pelas normas NBR 5739/1994, NBR 7222/2010 e NBR 8522/2008 respectivamente. As Figuras 2 a 4 ilustram os resultados obtidos. 


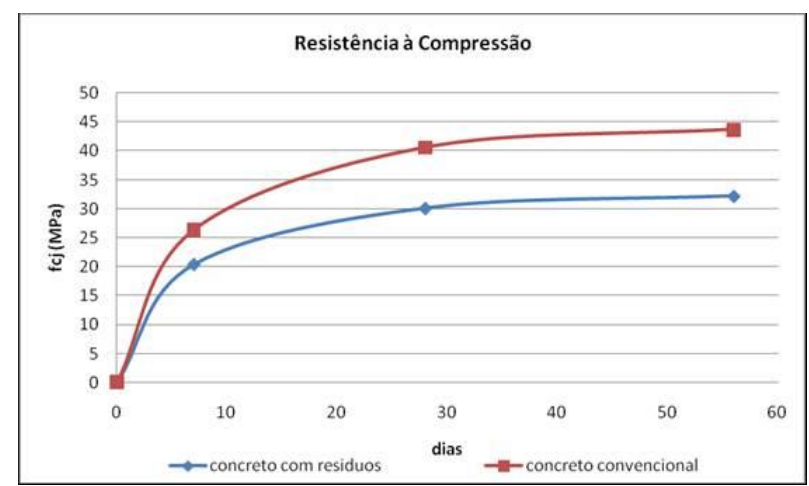

Figura 2 - Resistência à Compressão

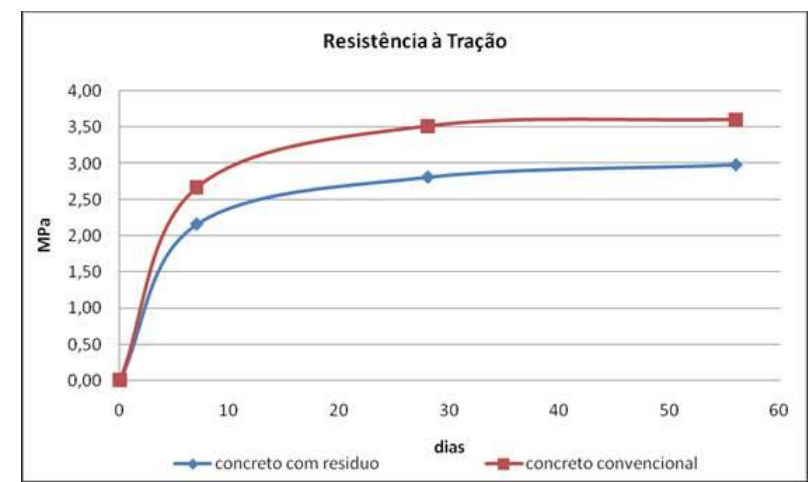

Figura 3 - Resistência à Tração

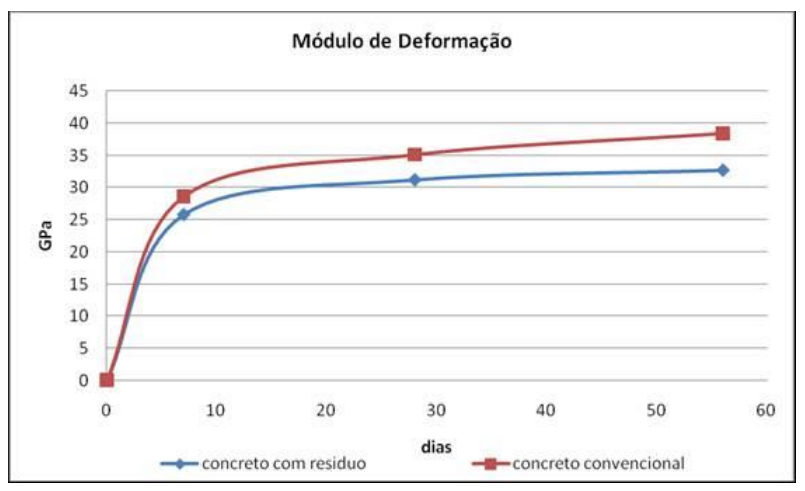

Figura 4 - Módulo de Deformação

\section{Estacas escavadas.}

As estacas foram escavadas no campo experimental da UNESP - Universidade Estadual Paulista na cidade de Ilha Solteira - SP, o município possui uma camada de solo superficial residual de basalto, altamente poroso e colapsível, que ocorre em mais de $60 \%$ da área do solo superficial do Estado de São Paulo, ver a Figura 5 ( Souza, 2001). 


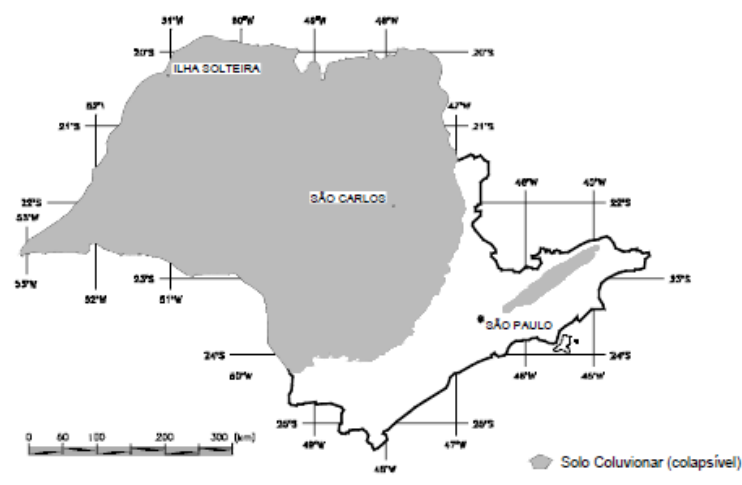

Figura 5 - Mapa do estado de São Paulo, localização da cidade de estudo.

As estacas de reação foram executadas em 2006 possui profundidade de 8,0 metros e diâmetro de 35 centímetros a estaca é armada em sua totalidade com aço CA-50-A de diâmetro de 10,0 mm com estribos a cada 15 centímetros de diâmetro de 6,3 mm com tirante para ancoragem.

Para perfuração com trado mecânico rotativo, foi contratada empresa particular e especialista em estacas escavadas. Antes da perfuração a locação das estacas foram conferidas e estudadas a posição do caminhão para não tocar as estacas de reação. $A$ figura 6 ilustra o posicionamento do caminhão e os preparativos para perfuração.
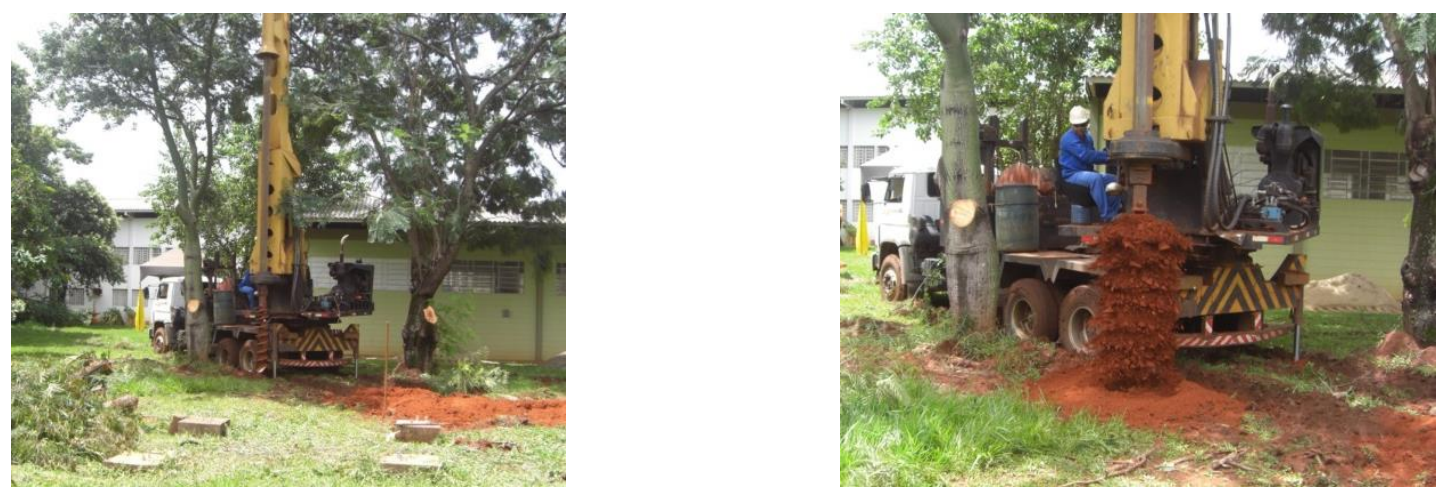

Figura 6 - Posicionamento do caminhão para perfuração. Fonte: Arquivo pessoal.

Logo após o término da perfuração instalou-se no fundo da estaca uma placa de isopor com espessura de 30 milímetros a fim de facilitar a identificação da resistência de ponta da estaca então instalou-se a armadura anteriormente preparada e efetuou-se a concretagem. 
Vale salientar que todas as barras foram instrumentadas, cada uma recebeu três extensômetros o primeiro a trinta centímetros do topo o segundo a um metro e vinte e o terceiro a cinco metros e setenta centímetros da ponta, com a finalidade de conhecermos as cargas nestes pontos.

\section{Resultados.}

Com os resultados obtidos nas provas de carga levadas até a ruptura, cujos resultados são mostrados nas Tabelas 3 e 4, foi possível plotar a curva de carga versus recalque de cada estaca (Figura 7), sendo as impares 1, 3 e 5 confeccionadas em concreto convencional e as pares 2, 4 e 6 em concreto com resíduo de borracha. 
Tabela 3 - Carga aplicada e recalque sofrido - Estacas de concreto convencional (C).

\begin{tabular}{|c|c|c|c|c|c|}
\hline \multicolumn{2}{|c|}{ PC-1 (C) } & \multicolumn{2}{|c|}{ PC-3 (C) } & \multicolumn{2}{|c|}{ PC-5 (C) } \\
\hline $\begin{array}{c}\text { Carga } \\
(\mathrm{kN})\end{array}$ & $\begin{array}{c}\rho \\
(\mathrm{mm})\end{array}$ & $\begin{array}{c}\text { Carga } \\
(\mathrm{kN})\end{array}$ & $\begin{array}{c}\rho \\
(\mathbf{m m})\end{array}$ & $\begin{array}{c}\text { Carga } \\
\text { (kN) }\end{array}$ & $\begin{array}{c}\rho \\
(\mathrm{mm})\end{array}$ \\
\hline 0 & 0,00 & 0 & 0,00 & 0 & 0,00 \\
\hline 10 & 0,05 & 10 & 0,05 & 10 & 0,06 \\
\hline 20 & 0,12 & 20 & 0,13 & 20 & 0,14 \\
\hline 30 & 0,21 & 30 & 0,27 & 30 & 0,31 \\
\hline 40 & 0,44 & 40 & 0,49 & 40 & 0,53 \\
\hline 50 & 1,03 & 50 & 1,09 & 50 & 1,26 \\
\hline 60 & 3,12 & 60 & 2,19 & 60 & 3,28 \\
\hline 70 & 7,40 & 70 & 6,54 & 70 & 8,71 \\
\hline 80 & 14,92 & 80 & 13,09 & 80 & 17,42 \\
\hline 90 & 25,00 & 90 & 22,50 & 90 & 27,72 \\
\hline 100 & 36,40 & 100 & 31,82 & 100 & 40,00 \\
\hline 110 & 44,47 & 110 & 42,01 & 110 & 45,22 \\
\hline 120 & 45,96 & 120 & 47,15 & 120 & 46,84 \\
\hline 130 & 46,88 & 130 & 47,75 & 130 & 47,71 \\
\hline 140 & 47,51 & 140 & 48,42 & 140 & 48,40 \\
\hline 150 & 48,11 & 150 & 48,79 & 150 & 49,12 \\
\hline 160 & 48,40 & 160 & 49,13 & 160 & 50,55 \\
\hline 170 & 48,64 & 170 & 49,38 & 170 & 51,79 \\
\hline 180 & 49,25 & 180 & 49,90 & 180 & 52,88 \\
\hline 190 & 50,27 & 190 & 50,82 & 190 & 54,37 \\
\hline 200 & 51,39 & 200 & 51,28 & 200 & 55,95 \\
\hline 210 & 53,09 & 210 & 51,91 & 210 & 58,13 \\
\hline 220 & 55,75 & 220 & 53,58 & 220 & 61,40 \\
\hline 230 & 59,99 & 230 & 55,52 & 230 & 67,28 \\
\hline 240 & 69,10 & 240 & 59,42 & 240 & 77,20 \\
\hline 250 & 108,06 & 250 & 73,39 & 250 & 105,70 \\
\hline 250 & 133,27 & 260 & 106,81 & 250 & 129,41 \\
\hline 190 & 132,99 & 260 & 135,52 & 190 & 129,30 \\
\hline 130 & 132,46 & 190 & 135,32 & 130 & 129,11 \\
\hline 70 & 131,53 & 130 & 135,08 & 70 & 128,80 \\
\hline 0 & 130,72 & 70 & 134,53 & 0 & 128,26 \\
\hline- & - & 0 & 133,54 & - & - \\
\hline
\end{tabular}

$\rho=$ recalque 
Tabela 4 - Carga aplicada e deslocamento - Estaca concreto com borracha (C+B).

\begin{tabular}{|c|c|c|c|c|c|}
\hline \multicolumn{2}{|c|}{ PC-2 (C+B) } & \multicolumn{2}{c|}{ PC-4 (C+B) } & \multicolumn{2}{c|}{ PC-6 (C+B) } \\
\hline $\begin{array}{c}\text { Carga } \\
\mathbf{( k N )}\end{array}$ & $\begin{array}{c}\boldsymbol{\rho} \\
(\mathbf{m m})\end{array}$ & $\begin{array}{c}\text { Carga } \\
\mathbf{( k N )}\end{array}$ & $\begin{array}{c}\mathbf{\rho} \\
(\mathbf{m m})\end{array}$ & $\begin{array}{c}\text { Carga } \\
(\mathbf{k N})\end{array}$ & $\begin{array}{c}\mathbf{\rho} \\
(\mathbf{m m})\end{array}$ \\
\hline 0 & 0,00 & 0 & 0,00 & 0 & 0,00 \\
\hline 10 & 0,04 & 10 & 0,04 & 10 & 0,12 \\
\hline 20 & 0,11 & 20 & 0,10 & 20 & 0,24 \\
\hline 30 & 0,21 & 30 & 0,23 & 30 & 0,45 \\
\hline 40 & 0,47 & 40 & 0,73 & 40 & 1,45 \\
\hline 50 & 1,08 & 50 & 1,61 & 50 & 2,88 \\
\hline 60 & 3,24 & 60 & 3,11 & 60 & 5,78 \\
\hline 70 & 7,62 & 70 & 6,79 & 70 & 10,00 \\
\hline 80 & 15,29 & 80 & 13,79 & 80 & 17,51 \\
\hline 90 & 23,99 & 90 & 23,38 & 90 & 29,13 \\
\hline 100 & 33,23 & 100 & 34,91 & 100 & 40,40 \\
\hline 110 & 44,06 & 110 & 42,19 & 110 & 45,02 \\
\hline 120 & 45,63 & 120 & 43,89 & 120 & 46,27 \\
\hline 130 & 46,97 & 130 & 45,19 & 130 & 46,99 \\
\hline 140 & 47,80 & 140 & 46,45 & 140 & 47,52 \\
\hline 150 & 49,30 & 150 & 47,72 & 150 & 48,24 \\
\hline 160 & 50,27 & 160 & 49,32 & 160 & 48,63 \\
\hline 170 & 51,17 & 170 & 51,47 & 170 & 49,85 \\
\hline 180 & 52,24 & 180 & 54,00 & 180 & 50,74 \\
\hline 190 & 53,70 & 190 & 57,14 & 190 & 51,92 \\
\hline 200 & 55,67 & 200 & 60,65 & 200 & 54,48 \\
\hline 210 & 57,62 & 210 & 65,14 & 210 & 60,69 \\
\hline 220 & 61,45 & 220 & 70,89 & 220 & 68,73 \\
\hline 230 & 67,44 & 230 & 95,64 & 230 & 102,39 \\
\hline 240 & 102,03 & 230 & 128,44 & 230 & 131,99 \\
\hline 240 & 137,04 & 190 & 128,35 & 190 & 131,76 \\
\hline 190 & 136,90 & 130 & 127,72 & 130 & 130,84 \\
\hline 130 & 136,78 & 70 & 126,88 & 70 & 129,04 \\
\hline 70 & 136,34 & 0 & 125,22 & 0 & 127,53 \\
\hline 0 & 134,83 & - & - & - & - \\
\hline & & & & & \\
\hline
\end{tabular}

$\rho=$ deslocamentos 


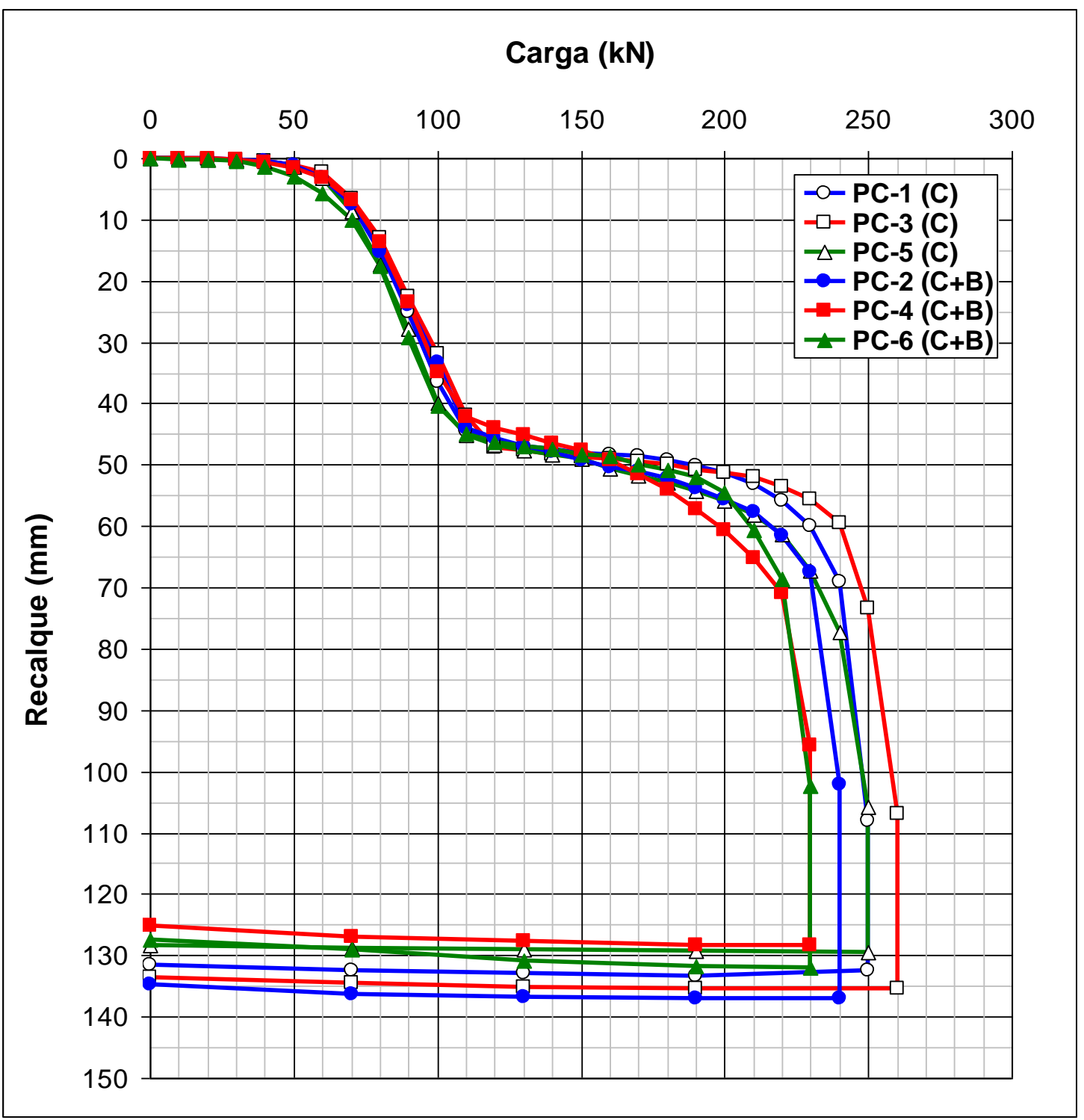

Figura 7 - Curvas carga versus recalque dos dois tipos de estacas..

Observando a Figura 7 com as curvas de carga versus recalque, dos dois tipos de estaca, conclui-se que as mesmas apresentam comportamento similar. Pode-se observar que as estacas que utilizaram em sua composição o resíduo de borracha apresentaram praticamente o mesmo recalque comparado com a estaca de concreto convencional até o carregamento próximo $100 \mathrm{kN}$. Para cargas superiores a este valor observa-se que o recalque para as estaca com borracha é levemente superior, em média $22 \%$ ao da estaca em concreto convencional. 


\section{CONCLUSÃO}

Com as analises sobre carga recalque conclui-se que o comportamento de ambas as estacas estudadas são similares, apesar da estaca em concreto com resíduo de borracha apresentar um maior recalque que a convencional, a diferença não é muito discrepante, ou seja, não impossibilita a sua utilização, principalmente em cargas até 100 $\mathrm{kN}$ onde os recalques foram praticamente os mesmos para ambas as estacas.

As cargas de ruptura médias obtidas nas provas de carga realizadas com as estacas de concreto convencional foi de $253,3 \mathrm{kN}$, já para as estacas de concreto com resíduo de borracha foi de $233,3 \mathrm{kN}$, portanto um diferença de $20 \mathrm{kN}$, ou seja $7,9 \%$. Este fato possivelmente se deve a maior deformabilidade da estaca de concreto com borracha, que proporcionou uma carga maior na ponta.

As curvas de carga versus recalque obtidas nas provas de carga para as estacas confeccionadas com os dois tipos de concreto apresentaram comportamento similar. Até a carga de $100 \mathrm{kN}$, já para cargas superiores o recalque das estaca de concreto com borracha foi levemente superior, em média $22 \%$ ao da estaca em concreto convencional.

O patamar que se observa entre as cargas de 100 e 200 kN se deve a instalação da pastilha de isopor na ponta da estaca, portanto em algum trecho deste patamar iniciouse a transferência de carga também pela ponta.

As cargas de ruptura (253,3 kN e 233,3 kN) quando comparadas com estimadas realizadas por métodos empíricos conclui-se que o método Aoki e Velloso (1975), baseado tanto em valores de SPT (138 kN) quanto em valores de CPT (137 kN), subestimaram bastante as cargas de ruptura, já o método de Décourt e Quaresma (1978), que resultou em $247 \mathrm{kN}$, foi extremamente preciso para as estacas de concreto e ligeiramente acima para as estacas de concreto com resíduo de borracha. 
Portanto pode-se concluir que é uma boa opção a utilização do resíduo de borracha do pneu, pois além de dar um destino ambientalmente correto ainda colabora de forma expressiva com a redução de extração de areia, recurso não renovável.

\section{REFERÊNCIAS}

ANIP - ASSOCIAÇÃO NACIONAL DAS INDÚSTRIAS PNEUMATICAS - In: Boletim Informativo da Bolsa de Reciclagem Sistema FIEP, 2006. Disponível: http://www.anip.com.br/?cont=conteudo\&area=32\&titulo pagina=Produção. Acesso: 13/08/2013

AOKI, N.; VELLOSO, D.A. An approximate method to estimate the bearing capacity of piles. In: PANAMERICAN CONFERENCE ON SOIL MECHANICS AND FOUNDATION ENGINEERING, 5, Buenos Aires, Proceedings, Buenos Aires, 1975, v. 1, p. 367-376.

ASSOCIAÇÃO BRASILEIRA DE NORMAS TÉCNICAS. NBR-12131: Estacas - Provas de Carga Estática, Rio de Janeiro, 1991, 4 p

ASSOCIAÇÃO BRASILEIRA DE NORMAS TÉCNICAS. NBR 11578: Cimento Portland Composto. Rio de Janeiro, 1997

ASSOCIAÇÃO BRASILEIRA DE NORMAS TÉCNICAS. NBR-6122: Estacas - Projeto e Execução de Fundações, Rio de Janeiro, 2010, 33 p.

ASSOCIAÇÃO BRASILEIRA DE NORMAS TÉCNICAS. NBR 5739: Concreto - Ensaio de Compressão de Corpos-de-Prova Cilíndricos. Rio de Janeiro, 1994.

ASSOCIAÇÃO BRASILEIRA DE NORMAS TÉCNICAS. NBR 7222: Argamassa e concreto-Determinação da resistência à tração por compressão diametral de corpos-de-prova cilíndricos. Rio de Janeiro, 1994.

ASSOCIAÇÃO BRASILEIRA DE NORMAS TÉCNICAS. NBR 8522: Concreto Determinação do Módulo de Deformação Estatística e Diagrama TensãoDeformação - Rio de Janeiro, 1984.

DÉCOURT, L.; QUARESMA, A.R. Capacidade de carga de estacas a partir de valores de SPT. In: CONGRESSO BRASILEIRO DE MECÂNICA DOS SOLOS E ENGENHARIA DE FUNDAÇÕES, 6, Rio de Janeiro, ABMS, Anais, Rio de Janeiro, 1978, p. 15-53.

SOUZA, A. Estaca piloto instrumentada: uma ferramenta para o estudo da capacidade de carga de estacas quando submetidas a esforços axiais de compressão. São Paulo 2001, 295f. Tese (Doutorado) - Escola Politécnica da Universidade de São Paulo. 